\title{
Remarks about the Appearance of Mars in the Tomb of Senenmut in Western Thebes
}

\author{
By Christian Leitz*
}

In an article recently published in this journal Ove von Spaeth (2000) discussed the well-known star map in the tomb of Senenmut at Thebes (TT 353). He proposed a new dating of this map (1534 BC) approximately 70 years earlier than the author of the present contribution (1463 BC). ${ }^{1}$ The latter date is in accordance with the generally accepted chronology of the 18th dynasty. ${ }^{2}$ The reason for this difference is due to a special assumption: Since Ove von Spaeth is convinced to have discovered the planet Mars in retrograde movement in the Senenmut ceiling, he can effectuate entirely new calculations leading to completely different results about the dating of the star map. Because all of his predecessors denied the presence of Mars in this ceiling a closer look to his arguments seems to be appropriate.

In the southern ceiling panel (his fig. 2 on p. 163) he described an empty boat in the west traditionally interpreted as an Egyptian constellation related to the surrounding decans. In contrary to this opinion von Spaeth suggested that this boat represents the planet Mars in its retrograde movement. But Mars is neither depicted like the two other planets Jupiter and Saturn as a falcon headed deity nor is its name (in that period Horakhti: "Horus of the horizon", later Hor desher: "Horus, the red one") written above the boat like the two other ones. Instead of this von Spaeth found an inscription between the names of the decans which he translates as "The

\footnotetext{
* Seminar für Ägyptologie, Universität zu Köln, Meister-Ekkehart-Strasse 7, 50923 Köln, Deutschland.
} 
red travels/sails south (tjemes khentet)" - in his view a designation for the always red planet Mars.

Unfortunately this translation is not acceptable. The expression tjemes khentet or more completely as in the Senenmut ceiling tjemes en khentet is a name of a decan and part of a greater constellation. The philologically correct translation is "the red one of the khentet-constellation". This decan appears on some Middle Kingdom coffin $\operatorname{lids}^{3}$ as well as in the SenenmutFamily of decans, i.e., the Seti I A Family, the Seti I C Family, and the Seti I B Family. ${ }^{4}$ There is a multitude of examples showing both the representation of Mars as third falcon headed deity in a boat behind Jupiter and Saturn and the decan tjemes en khentet among the other decans. ${ }^{5}$ The use of en between tjemes and khentet makes it quite clear that this is the genetival adjective. Therefore, the translation of Ove von Spaeth can not be supported from a philological point of view.

Consequently, it must be stated that all the calculations of von Spaeth are based on a wrong assumption (presence of Mars in retrograde movement).

For the sake of completeness his alleged solar eclipse shall be regarded. ${ }^{6}$ Above the representation of Orion he finds after the decan no. 31 the hieroglyphs iret Hor: "Eye of Horus". This is correct. His interpretation, however, that this is an indication of a solar eclipse is far-fetched. As a matter of fact each of the 36 decans is accompanied by an Egyptian Deity. In the case of decan no. 31 it is accompanied by the Eye of Horus. An overview about all these deities has already been presented by Neugebauer and Parker. ${ }^{7}$ The same consideration applies for the inscription following decan no. 32. This is not the "birthday of Horus" 8 and an indication of the new moon during the solar eclipse, but simply the "children of Horus". 9 "

To conclude: It might be helpful to ask one or two egyptologists before starting such calculations leading to far going conclusions which are completely unfounded.

\section{BIBLIOGRAPHY}

von Beckerath, J.

1997: Chronologie des pharaonischen Ägypten, Münchner Ägyptologische Studien, vol. 46, Mainz.

Leitz, C.

1991: Studien zur ägyptischen Astronomie, Ägyptologische Abhandlungen, vol. 49, 2. Aufl. Wiesbaden (1989), pp. 35-48. 
Leitz, C.

1995: Altägyptische Sternuhren, Orientalia Lovaniensia Analecta, vol. 62, Leuven 1995.

Neugebauer, O. and Parker, R. A.

1960: Egyptian Astronomical Texts, vol. I: The Early Decans, Brown Egyptological Studies 3, London 1960.

Neugebauer, O. and Parker, R. A.

1969: Egyptian Astronomical Texts, vol. III: Decans, Planets, Constellations and Zodiacs, Brown Egyptological Studies 6, London 1969.

von Spaeth, O.

2000: Dating the Oldest Egyptian Star Map, Centaurus, vol. 42, pp. 159-179.

\section{NOTES}

1. Leitz 1991, pp. 35-48.

2. von Beckerath 1997, p. 126.

3. Neugebauer and Parker 1960, pl. 26.

4. Neugebauer and Parker 1969, pp. 109, 121, 130, 136. For a possible identification of this red star see Leitz 1995, pp. 88-89.

5. E.g. Neugebauer and Parker 1969, pl. 3, 5 and 12.

6. von Spaeth 2000, pp. 171-174.

7. Neugebauer and Parker 1969 , pp. 153-156.

8. von Spaeth 2000, 174.

9. Neugebauer and Parker 1969, p. 153 with a list of several decans which are associated with the children of Horus. 